\title{
Transient Increase in Endothelin-1 Levels in the Pulmonary Circulation during Exercise While Breathing of Oxygen in Patients with Chronic Obstructive Pulmonary Disease
}

\author{
Hiroshi Kanazawa, Kazuto Hirata and Junichi YoshiKawa
}

\begin{abstract}
Objective The effects of endothelin-1 (ET-1) on pulmonary vascular tone depend on the complex interplay of ET1-induced vasoconstriction and vasodilation due to the secondary generation of endothelium-derived vasorelaxants. Therefore, it is likely that the response to ET-1 varies, depending on whether it is applied to the luminal or adventitial side of pulmonary vessels. Therefore, this study was designed to determine the change in luminal ET-1 levels during exercise in patients with chronic obstructive pulmonary disease (COPD).

Methods All subjects performed a constant-load exercise test for 5 minutes on the ergometer with right heart catheterization while breathing room air or oxygen. ET-1 levels at rest, just after exercise, and 1 hour after exercise were measured in the pulmonary capillary wedge region.

Patients Thirty-six patients with COPD.

Results While breathing room air, ET-1 levels did not significantly differ between at rest, just after exercise and 1 hour after exercise [at rest; $4.15(0.43) \mathrm{pg} / \mathrm{ml}$, just after exercise; $4.15(0.44) \mathrm{pg} / \mathrm{ml}, 1$ hour after exercise; $4.13(0.42)$ $\mathrm{pg} / \mathrm{ml}]$. In contrast, while breathing oxygen, ET- 1 levels were significantly higher just after exercise $[4.41(0.43) \mathrm{pg} / \mathrm{ml}]$ than at rest $[3.90(0.37) \mathrm{pg} / \mathrm{ml}, \mathrm{p}=0.0116]$ and 1 hour after exercise $[3.93(0.38) \mathrm{pg} / \mathrm{ml}, \mathrm{p}=0.0246]$. The change in ET-1 levels between before and just after exercise $(\triangle E T-1)$ was negatively correlated with change in $\mathrm{mPAP}(\triangle \mathrm{mPAP})(\mathrm{r}=-$ $0.638, p=0.0001)$. However, $\triangle E T-1$ was not significantly correlated with any FEV1 (\% predicted), DLCO, $\mathrm{PaO}_{2}$, or baseline pulmonary hemodynamics.

Conclusion The impairment of ET-1 release into the luminal side was observed in patients with COPD during exercise while breathing room air. However, oxygen supplementation reversed the capacity of ET-1 release, and $\triangle E T$ 1 with exercise was negatively correlated with $\triangle$ mPAP. (Internal Medicine 41: 522-525, 2002)
\end{abstract}

Key words: pulmonary hypertension, vasodilation, right heart catheterization, luminal side

\section{Introduction}

Vascular endothelial cells release both vasoconstrictor and vasodilator substances, thereby adjusting the local vascular tone. Most potent among endothelium-derived vasoconstrictors is endothelin-1 (ET-1), a 21 amino-acid peptide originally isolated from porcine aortic cell cultures (1). Like other endothelium, pulmonary endothelial cells contain preproET-1 (ppET1) mRNA and appear to release ET-1, which likely contributes to basal pulmonary vascular tone. The net effect on pulmonary vascular tone likely depends on the complex interplay of ET-1induced vasoconstriction and vasodilation due to the secondary generation of prostacyclin and possibly nitric oxide (NO) $(2,3)$.

Patients with secondary pulmonary hypertension due to chronic obstructive pulmonary disease (COPD) have increased immunostaining for ET-1 in the endothelium of elastic and muscular pulmonary arteries (4). Additionally, they have elevated ppET-1 mRNA in their lungs compared with normal subjects. Though patients with pulmonary hypertension also have elevated plasma ET-1 levels (5), their ET-1 levels do not correlate with the magnitude of pulmonary hypertension, pulmonary vascular resistance, or right ventricular ejection fraction (6). Indeed, cultured endothelial cells release the vast majority of ET- 1 towards the vascular smooth muscle (7), and little information exists concerning the in vivo physiologic role of luminal ET-1 in the pulmonary circulation. It is likely that the response to ET-1 varies, depending on whether it is applied to the luminal or adventitial side of pulmonary vessels. Therefore, this study was designed to determine the change in luminal ET-1 levels during exercise on breathing room air or oxygen in patients with COPD.

From the Department of Respiratory Medicine, Graduate School of Medicine, Osaka City University, Osaka

Received for publication October 3, 2001; Accepted for publication March 29, 2002

Reprint requests should be addressed to Dr. Hiroshi Kanazawa, the Department of Respiratory Medicine, Graduate School of Medicine, Osaka City University, 1-4-3 Asahi-machi, Abeno-ku, Osaka 545-8585 


\section{ET-1 Levels during Exercise in COPD}

\section{Material and Methods}

Thirty-six patients with COPD (all males) from the respiratory outpatient clinic of our institution were enrolled in this study. They had a history of former smoking and irreversible airflow limitation. All patients satisfied the American Thoracic Society criteria for COPD (8). Patients with evidence of coronary artery disease, valvular heart disease, systemic hypertension, or primary myocardial disease were excluded from the study. None of the study subjects had radiologic or clinical evidence of pulmonary congestion or right heart failure. Concomitant left ventricular dysfunction was excluded in all patients by echocardiography performed prior to the study. All patients with COPD were clinically stable, and none had a history of respiratory infection for at least the 4-week period preceding the study. All patients gave their written informed consent for participation in this study, which was approved by the Ethics Committee of Osaka City University.

On the first day of the study, the subjects underwent a progressive incremental exercise test while sitting on an ergometer (EM840; Siemens; Munich, Germany), starting at $0 \mathrm{~W}$ for 3 minutes and adding $10 \mathrm{~W}$ every minute until a symptomlimited maximum was reached, as previously described (9). Heart rate (HR) was continuously monitored using standard electrocardiographic equipment. The purpose of this incremental exercise test was to determine the maximal exercise capacity. On the day following the test, all subjects underwent right heart catheterization. All cardiopulmonary medications were withheld for at least 12 hours before the study. A balloon-tipped pulmonary arterial catheter was inserted percutaneously into an internal jugular vein and advanced to the pulmonary artery for measurement of pulmonary arterial pressure (PAP) and ET1 levels. In addition, a plastic catheter was placed percutaneously into the brachial artery to monitor systemic arterial pressure (SAP) and sample systemic arterial blood. HR and heart rhythm were monitored continuously. Intravascular pressures were measured using a transducer (Baxter, UK901, Tokyo) located at the level of the anterior fourth intercostal space, with the patient sitting upright, and recorded on photographic paper. Pressures were averaged over three respiratory cycles. Mean pressures were obtained by electronic integration. Arterial blood gas tensions were measured with a blood gas analyzer (Model IL 1312; Instrumentation Laboratory, Tokyo). Resting hemodynamic and blood gas data were obtained about 20 minutes after the patient had been seated comfortably on the ergometer. Each patient then performed a constant-load exercise test for 5 minutes while on the ergometer at a workload corresponding to $60 \%$ of the previously determined maximal workload. Hemodynamic and blood gas measurements were performed during the final minute of constant-load exercise. After exercise while breathing of room air, $100 \%$ oxygen was given to the patients for 60 minutes via nasal cannula at a rate of $3 l l$ $\mathrm{min}$. All of the protocols described earlier were repeated while the patients breathed oxygen.

At rest, just after exercise, and 1 hour after exercise, a blood sample $(10 \mathrm{ml})$ was drawn into ice-chilled siliconized disposable glass tubes containing Trasylol $\left(5 \times 10^{5}\right.$ kallikrein inactivator units $/ l)$ and ethyldiaminetetraacetic àcid $(1 \mathrm{~g} / l)$. Plasma was separated by centrifugation for 15 minutes at $4^{\circ} \mathrm{C}$ and immediately frozen and stored at $-80^{\circ} \mathrm{C}$ for several days. Immunoreactive ET-1 was assayed as previously described (10).

All values are presented as the means (SD). Statistical analysis was performed among the groups by one-way analysis of variance (ANOVA). When ANOVA revealed a significant difference, Bonferroni's correction was applied. The significant level was set at $\mathrm{p}<0.05$.

\section{Results}

The pulmonary function and hemodynamic data for 36 study

Table 1. Clinical Characteristics of Patients in the Study

\begin{tabular}{|c|c|c|}
\hline \multicolumn{2}{|l|}{ Age (years) } & $62.8(4.6)$ \\
\hline \multicolumn{2}{|c|}{ FEV1 (\% predicted) } & $52.0(12.5)$ \\
\hline \multicolumn{2}{|l|}{$\operatorname{DLCO}(\%)$} & $53.0(14.0)$ \\
\hline \multicolumn{3}{|l|}{$\mathrm{PaO}_{2}(\mathrm{mmHg})$} \\
\hline \multirow[t]{2}{*}{ room air } & (rest) & $60.8(7.0)$ \\
\hline & (post-exercise) & $48.4(5.7)^{* *}$ \\
\hline \multirow[t]{2}{*}{ oxygen } & (rest) & $92.5(8.5)^{\# \#}$ \\
\hline & (post-exercise) & $77.4(6.0)^{* * \# \#}$ \\
\hline \multicolumn{3}{|c|}{$\mathrm{PaCO}_{2}(\mathrm{mmHg})$} \\
\hline \multirow[t]{2}{*}{ room air } & (rest) & $39.0(2.9)$ \\
\hline & (post-exercise) & $42.9(3.4)^{* *}$ \\
\hline \multirow[t]{2}{*}{ oxygen } & (rest) & $39.5(3.3)$ \\
\hline & (post-exercise) & $44.2(3.8)^{* *}$ \\
\hline \multicolumn{3}{|l|}{ MAP $(\mathrm{mmHg})$} \\
\hline \multirow[t]{2}{*}{ room air } & (rest) & $93.0(8.5)$ \\
\hline & (post-exercise) & $140.0(13.4)^{* *}$ \\
\hline \multirow[t]{2}{*}{ oxygen } & (rest) & $92.2(8.6)$ \\
\hline & (post-exercise) & $133.4(16.9)^{* * \#}$ \\
\hline \multicolumn{3}{|l|}{ HR } \\
\hline \multirow[t]{2}{*}{ room air } & (rest) & $76.8(10.7)$ \\
\hline & (post-exercise) & $114.9(17.0)^{*}$ \\
\hline \multirow[t]{2}{*}{ oxygen } & (rest) & $75.8(10.7)$ \\
\hline & (post-exercise) & $112.4(16.7)^{* *}$ \\
\hline \multicolumn{3}{|c|}{$\operatorname{mPAP}(\mathrm{mmHg})$} \\
\hline \multirow[t]{2}{*}{ room air } & (rest) & $27.0(2.6)$ \\
\hline & (post-exercise) & $45.9(7.0)^{* *}$ \\
\hline \multirow[t]{2}{*}{ oxygen } & (rest) & $22.4(3.3)^{\# \#}$ \\
\hline & (post-exercise) & $41.3(6.4)^{* * \# \#}$ \\
\hline \multicolumn{3}{|c|}{$\operatorname{PVR}\left(\mathrm{mmHg} / l / \mathrm{min} / \mathrm{m}^{2}\right)$} \\
\hline \multirow[t]{2}{*}{ room air } & (rest) & $7.75(0.64)$ \\
\hline & (post-exercise) & $8.92(1.70)^{* *}$ \\
\hline \multirow[t]{2}{*}{ oxygen } & (rest) & $7.48(0.74)$ \\
\hline & (post-exercise) & $7.96(1.65)^{* \# \#}$ \\
\hline
\end{tabular}

Data are presented as mean (SD). FEV1: forced expiratory volume in one second, DLCO: diffusing capacity of carbon monoxide, $\mathrm{PaO}_{2}$ : arterial oxygen tension, $\mathrm{PaCO}_{2}$ : arterial carbon dioxide tension, MAP: mean arterial pressure, HR: heart rate, mPAP: mean pulmonary arterial pressure, PVR: pulmonary vascular resistance .PVR; PAP-pulmonary capillary wedge pressure $] /$ cardiac index. ${ }^{*} \mathrm{p}<0.05,{ }^{*} \mathrm{p}<0.01$ compared with rest. ${ }^{\#} \mathrm{p}<0.05,{ }^{\#} \mathrm{p}<0.01$ compared with room air. 


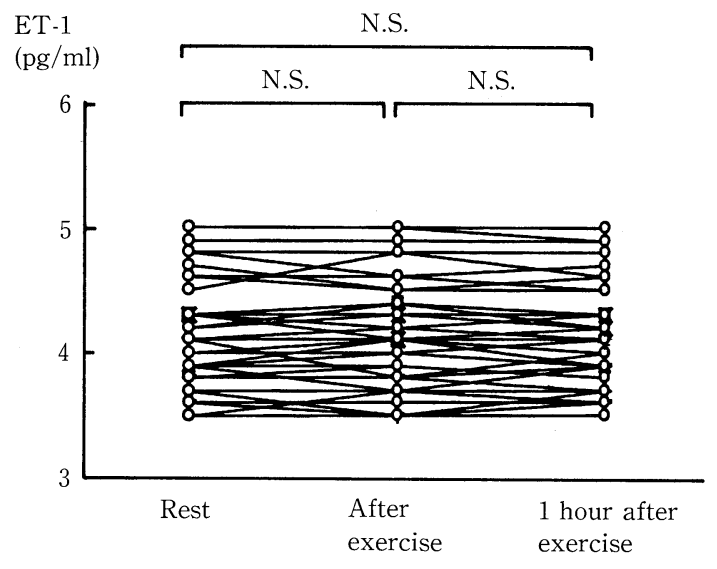

Room air

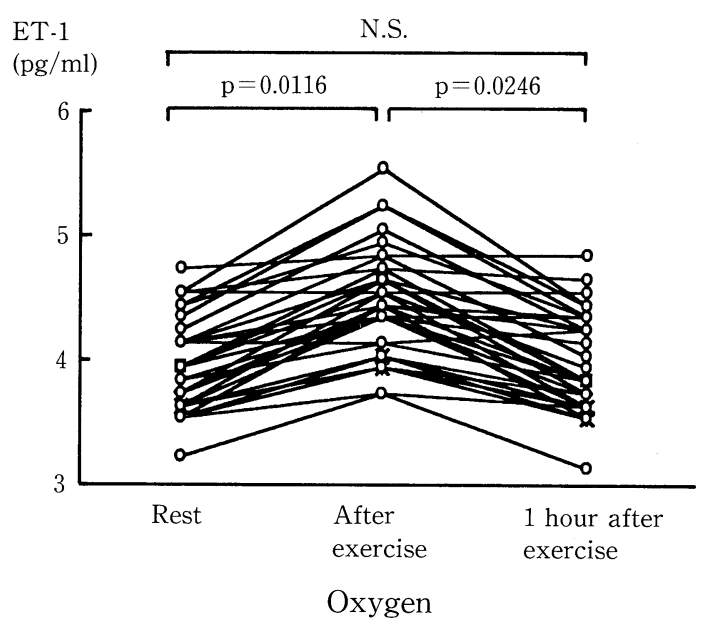

Figure 1. Comparison of ET-1 levels at rest, just after exercise, and 1 hour after exercise while breathing room air or oxygen.

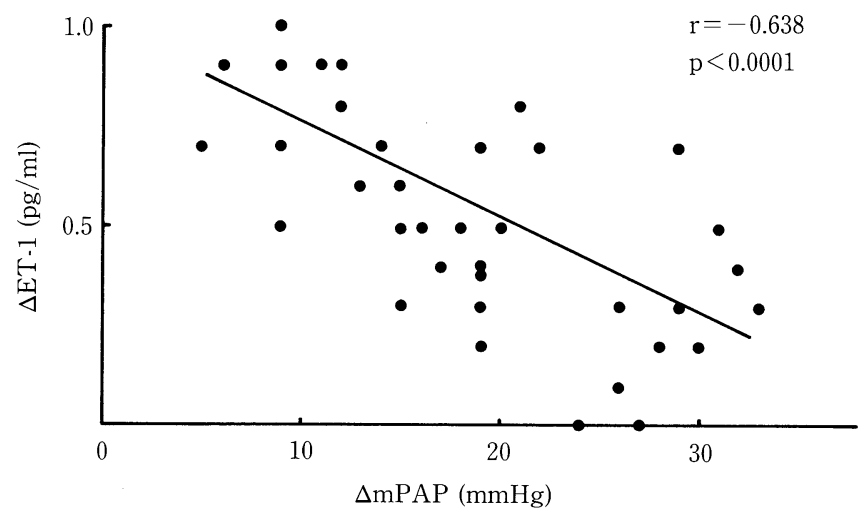

Figure 2. Correlation between the change in ET-1 level during exercise $(\triangle \mathrm{ET}-1)$ and change in $\mathrm{mPAP}(\triangle \mathrm{MPAP})$ while breathing oxygen.

subjects with COPD are shown in Table 1. Baseline spirometry revealed the presence of obstructive defects in all patients [FEV1 (l); 0.81 (0.20), FEV1 (\% predicted); 52.0 (12.5)]. The $\mathrm{PaO}_{2}$ at rest was $60.8(7.0) \mathrm{mmHg}$, but hypoxemia was found after exercise testing [ $48.4(5.7) \mathrm{mmHg}$ ]. The mPAP at rest revealed mild hypertension in all patients [room air; 27.0 (2.6) mmHg, oxygen; 22.4 (3.3) $\mathrm{mmHg}$ ]. After exercise testing, the mPAP increased markedly in all patients [room air; 45.9 (7.0) mmHg, oxygen; 41.3 (6.4) $\mathrm{mmHg}$ ].

While breathing room air, ET-1 levels did not significantly differ between at rest, just after exercise and 1 hour after exercise [at rest; $4.15(0.43) \mathrm{pg} / \mathrm{ml}$, just after exercise; $4.15(0.44)$ $\mathrm{pg} / \mathrm{ml}, 1$ hour after exercise; 4.13 (0.42) pg/ml] (Fig. 1). In contrast, while breathing oxygen, ET-1 levels were significantly higher just after exercise [4.41 $(0.43) \mathrm{pg} / \mathrm{ml}]$ than at rest $[3.90$ (0.37) $\mathrm{pg} / \mathrm{ml}, \mathrm{p}=0.0116]$ and 1 hour after exercise [3.93 (0.38) $\mathrm{pg} / \mathrm{ml}, \mathrm{p}=0.0246]$. However, ET-1 levels at rest and 1 hour after exercise were significantly higher on breathing room air than those on breathing oxygen (at rest; $p=0.0116,1$ hour after exercise; $p=0.035$ ).

The change in ET-1 levels between before and just after exercise $(\triangle \mathrm{ET}-1)$ was negatively correlated with change in mPAP ( $\triangle \mathrm{mPAP})(\mathrm{r}=-0.638, \mathrm{p}=0.0001)$ (Fig. 2). However, $\Delta \mathrm{ET}-1$ was not significantly correlated with any FEV1 (\% predicted), DLCO, $\mathrm{PaO}_{2}$ (before or after exercise), or baseline pulmonary hemodynamics.

\section{Discussion}

In the present study, blood samples were collected from the pulmonary capillary wedge region to confirm circulating ET-1 levels in the pulmonary circulation. A previous study suggested that the ET-1 level in mixed venous plasma was $0.75(0.64) \mathrm{pg} /$ $\mathrm{ml}$ in patients with stable coronary disease but not no evidence of pulmonary hypertension (6). Celik and Karabiyikoglu found that the ET-1 level in the pulmonary artery was locally elevated in COPD patients with pulmonary hypertension, and that the ET-1 level in the radial artery and brachial vein of COPD patients, and in the pulmonary artery of COPD patients without pulmonary hypertension were within normal range (11). Moreover, Yoshibayashi et al also found that ET-1 levels were different at sampling sites in patients with secondary pulmonary hypertension, and they also noted an increasing ET-1 level from the right ventricle through the pulmonary vein in these patients, suggesting a local ET-1 production with the pulmonary vascular bed (12). Thus, it is very important to measure ET-1 levels at different sampling sites and transpulmonary difference of ET-1 levels. Though we simply measured the ET-1 levels at the pulmonary capillary wedge region in this study, chronic augmented ET-1 release [4.15 $(0.43) \mathrm{pg} / \mathrm{ml}]$ into the pulmonary circulation was observed even in the COPD patients with a slightly increased mPAP at rest. 


\section{ET-1 Levels during Exercise in COPD}

ET-1 has a dual action because it is a potent vasoconstrictor, but can also cause vasodilation mediated by the production of NO. The responses to ET-1 are mediated via the activation of two distinct receptor subtypes (13). The $\mathrm{ET}_{\mathrm{A}}$ receptors are located on vascular smooth muscle cells and mediate the constrictive effects, whereas the $\mathrm{ET}_{\mathrm{B}}$ receptors are located on the vascular endothelium and mediate vasodilation by increasing the production of NO (14). In fact, numerous studies indicate that providing exogenous ET-1 can reduce acute hypoxic pulmonary vasoconstriction. For example, ET-1 causes vasodilation during hypoxic pulmonary vasoconstriction in awake calves and conscious rats $(15,16)$. Postulated mechanisms of previous studies for reversing hypoxic pulmonary vasoconstriction include augmenting NO release. One could therefore speculate that the $\mathrm{ET}_{\mathrm{B}}$ receptors contribute to the regulation of pulmonary vascular tone, and that the change in ET-1 levels in the pulmonary circulation may reflect the $\mathrm{ET}_{\mathrm{B}}$ receptor-dependent relaxation of pulmonary arteries. Moreover, selective $\mathrm{ET}_{\mathrm{B}}$ receptor inhibition causes severe pulmonary hypertension (17). In the present study, we found that ET-1 levels just after exercise while breathing oxygen were significantly higher than those at rest, and that $\triangle \mathrm{mPAP}$ during exercise was negatively correlated with $\triangle E T-1$. In contrast, $\triangle$ mPAP was not significantly correlated with any FEV1 (\% predicted), DLCO, $\mathrm{PaO}_{2}$, or baseline pulmonary hemodynamics. Therefore, we speculated that transient release of ET-1 with exercise into the luminal side plays an important role in attenuating exercise-induced pulmonary hypertension. However, in this study, we did not determine NO levels in the pulmonary circulation with exercise while breathing room air or oxygen. Therefore, further studies using ET-1 receptor antagonists should be undertaken to confirm this issue. The mechanisms of impairment of ET-1 release into the luminal side with exercise while breathing room air are unclear. However, we found that 60 minutes of oxygen supplementation restored the impairment of ET-1 release into the luminal side with exercise. One could therefore speculate that the impairment of ET-1 release could be observed, at least in part, due to the effects of exercise-induced hypoxia.

In conclusion, the impairment of ET-1 release into the luminal side was observed in patients with COPD during exercise while breathing room air. Oxygen supplementation reversed the capacity of ET- 1 release; it might attenuate exaggerated pulmonary hypertension during exercise through transient ET1 release into the luminal side.

Acknowledgements: This work was supported by a grant-in-aid for Sci- entific Research (13670611) from the Ministry of Education, Science and Culture, Japan.

\section{References}

1) Yanagisawa $M$, Kurihara $H$, Kimura $S$, et al. A novel potent vasoconstrictor peptide produced by vascular endothelial cells. Nature 332: 411-415, 1988.

2) Webb DJ, Haynes WG. Venoconstriction to endothelin-1 in humans is attenuated by local generation of prostacyclin but not nitric oxide. $\mathrm{J}$ Cardiovasc Pharmacol 22 (Suppl. 89): S317-S320, 1993.

3) Kiowski W, Linder L, Stoschitzky K, et al. Diminished vascular response to inhibition of endothelium-derived nitric oxide and enhanced vasoconstriction to exogenously administered endothelin-1 in clinically healthy smokers. Circulation 90: 27-34, 1994.

4) Giaid A, Yanagisawa M, Langleben D, et al. Expression of endothelin-1 in the lungs of patients with pulmonary hypertension. N Engl J Med 328: 1732-1739, 1993.

5) Ferri $C$, Bellini $C$, De Angelis $C$, et al. Circulating endothelin- 1 concentrations in patients with chronic hypoxia. J Clin Pathol 48: 519-524, 1995.

6) Stewart DJ, Levy RD, Cernacek P, Langleben D. Increased plasma endothelin-1 in pulmonary hypertension: marker or mediator of disease? Ann Intern Med 114: 464-469, 1991.

7) Wagner OF, Christ G, Wojta J, et al. Polar secretion of endothelin- 1 by cultured endothelial cells. J Biol Chem 267: 16066-16068, 1992.

8) American Thoracic Society. Standards for the diagnosis and care of patients with chronic obstructive pulmonary disease (COPD) and asthma. Am Rev Respir Dis 136: 225-244, 1987.

9) Kanazawa H, Okamoto T, Hirata K, Yoshikawa J. Deletion polymorphisms in the angiotensin converting enzyme gene are associated with pulmonary hypertension evoked by exercise challenge in patients with chronic obstructive pulmonary disease. Am J Respir Crit Care Med 162: 1235$1238,2000$.

10) Kohno M, Yasunari K, Murakawa K, et al. Plasma immunoreactive endothelin in essential hypertension. Am J Med 88: 614-618, 1990.

11) Celik G, Karabiyikoglu G. Local and peripheral plasma endothelin-1 in pulmonary hypertension secondary to chronic obstructive pulmonary disease. Respiration 65: 289-294, 1998.

12) Yoshibayashi M, Nishioka $K$, Nakao K, et al. Plasma endothelin concentrations in patients with pulmonary hypertension associated with congenital heart defects. Evidence for increased production of endothelin in pulmonary circulation. Circulation 89: 2093-2098, 1994.

13) Arai H, Hori S, Aramori I, Ohkubo H, Nakanishi S. Cloning and expression of a cDNA encoding on endothelin receptor. Nature (London) 348 : 730-732, 1990.

14) Dohi $Y$, Luscher TF. Endothelin in hypertensive resistance arteries. Intraluminal extraluminal dysfunction. Hypertension 18: 543-549, 1991.

15) Deleuze PH, Adnot S, Shiiya N, et al. Endothelin dilates bovine pulmonary circulation and reverses hypoxic pulmonary vasoconstriction. $\mathrm{J}$ Cardiovasc Pharmacol 19: 354-360, 1992.

16) Hasunuma K, Rodman DM, O'Brien RF, McMurtry IF. Endothelin 1 causes pulmonary vasodilation in rats. Am J Physiol 259: H48-H54, 1990.

17) Ivy DD, Parker TA, Abman SH. Prolonged endothelin B receptor blokade causes pulmonary hypertension in the ovine fetus. Am J Physiol 279: L758-L765, 2000. 